\title{
On the use of the calibration-based approach for debris-flow forward-analyses
}

\author{
M. Pirulli \\ Department of Structural and Geotechnical Engineering, Politecnico di Torino, Corso Duca degli Abruzzi, 24, \\ Torino, 10129, Italy
}

Received: 26 November 2009 - Accepted: 14 April 2010 - Published: 12 May 2010

\begin{abstract}
In the present paper the problem of modeling the propagation of potential debris flows is tackled resorting to a numerical approach. In particular, numerical analyses are carried out with the RASH3D code, based on a single-phase depth-averaged continuum mechanics approach.

Since each numerical analysis requires the selection of a rheology and the setting of the rheological input parameters, a calibration-based approach, where the rheological parameters are constrained by systematic adjustment during trial-and-error back-analysis of full-scale events, has been assumed.

The back-analysis of a $1000 \mathrm{~m}^{3}$ debris flow, located at Tate's Cairn, Hong Kong, and the forward-analysis of a $10000 \mathrm{~m}^{3}$ potential debris flow, located in the same basin have been used to investigate the transferability of backcalculated rheological parameters from one case to another. Three different rheologies have been tested: Frictional, Voellmy and Quadratic.

From obtained results it emerges that 1) the backcalculation of a past event with different rheologies can help in selecting the rheology that better reproduces the runout of the analysed event and, on the basis of that selection, can give some indication about the dynamics of the investigated flow, 2) the use of back-calculated parameters for forward purposes requires that past and potential events have similar characteristics, some of which are a function of the assumed rheology. Among tested rheologies, it is observed that the Quadratic rheology is more influenced by volume size than Frictional and Voellmy rheologies and consequently its application requires that events are also similar in volume.
\end{abstract}

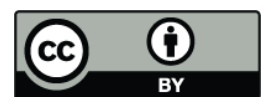

Correspondence to: M. Pirulli

(marina.pirulli@polito.it)

\section{Introduction}

Debris flows are made up of soil, rock, and water. Their flow characteristics, depending on the dynamic interaction between solid and fluid phases during propagation, are a function of the percentage of each of the above mentioned elements.

Since mechanisms that regulate such an interaction are not yet fully understood and their numerical implementation still remains a rather difficult task, currently available numerical models inevitably rely on simplifying assumptions. However there is a clear need for these models, as hazard evaluation or mitigation-measure design tools, because debris flows continue to cause significant damage in mountainous regions (Naef et al., 2006).

Existing runout prediction methods may be broadly categorized either as empirical or dynamic in nature. Empirical models are typically based on limiting criteria (e.g. Benda and Cundy, 1990; Fannin and Rollerson, 1993, 1996) or on statistical relations (e.g. Cannon, 1993; Rickenmann, 1999). Although they are often easy to use, they should only be applied to conditions similar to those on which their development is based (Rickenmann, 2005). Dynamic models may incorporate a rigid-body analysis, such as the mass-based approaches of Perla et al. (1980) and Van Gassen and Cruden (1989), or the energy-based approach of Körner (1980). Alternatively, dynamic models may consider a deformable-body approach using principles of continuum mechanics (e.g. Savage and Hutter, 1989; O'Brien et al., 1993; Hungr, 1995; Iverson and Denlinger, 2001; McDougall and Hungr, 2004), with the advantage of making possible the simulation of the deformation of the moving mass along the flow path, including deposition (Fannin and Wise, 2001).

It is probably fair to state that Savage and Hutter, in 1989, developed the first continuum mechanical theory capable of describing the evolving geometry of a finite mass of granular material and the associated velocity distribution as an avalanche slides down inclined surfaces.

Published by Copernicus Publications on behalf of the European Geosciences Union. 
Depth-averaging momentum and mass conservation equations, they obtained one-dimensional shallow-flow equations in a formulation in which a complete description of the flow is avoided and a Coulomb equation for basal shear resistance is assumed.

Subsequent generalizations of the Savage-Hutter approach have included extension to multidimensional flows, incrementally advancing to a stage in which reliable application to complex phenomena appears within reach. It results that many of the models developed in the past three decades are based on single-phase solutions of the above mentioned depth-averaged equations of motion and relatively simple single-phase rheological relationships, which define resistance acting at the base of the assumed depth-averaged flow (e.g. Chen and Lee, 2000; McDougall and Hungr, 2004; Denlinger and Iverson, 2004; Pirulli, 2005; Christen et al., 2007).

However, selecting a rheological relationship and setting values of its rheological parameters, to define the flow characteristics, still remain an open problem, that can be nowadays dealt with by following either a measurement-based approach or a calibration-based approach (McDougall et al., 2008).

Parameter measurement is advocated by workers who maintain that parameters to use for the analysis of real cases can be obtained through controlled laboratory experiments. Although it is scientifically appealing to be able to measure the input parameters, no standard experiments are available to measure, for example, the properties of complex debris flows travelling at extremely rapid velocities. Such properties, even if measurable, may be scale dependent.

That is why a calibration-based approach, where the rheological parameters are constrained by systematic adjustment during trial-and-error back-analysis of full-scale events, is pursued by many authors. In this frame, simulation of a historical event is typically achieved by matching the simulated travel distance, velocities and extent and depth of the deposit to those observed on site. The back-calculation of rheological parameters makes simpler the study of past complex phenomena like debris flows and provide calibrated input parameters to use for first-order runout forward-analyses. But, the effectiveness of their use in forward-analyses is however a function of the degree of similarity between historical and potential event characteristics.

It is demonstrated that flow composition (fluid vs. solid) and slope lithology and morphology influence the behaviour of a flow (e.g. Pirulli, 2010), so these aspects certainly have to be taken into consideration when similarity between two cases is being estimated.

In the present paper, a series of numerical analyses are instead carried out in order to investigate if the volume of the released mass can also be a factor to consider when assessing the similarity of two events. To this aim, the back analysis of a $1000 \mathrm{~m}^{3}$ debris flow, which took place at Tate's Cairn (Hong Kong) in August 2005, is undertaken with the onephase continuum-mechanics-based code RASH3D (Pirulli,
2005) and three different rheological laws are tested (Frictional, Voellmy, Quadratic). Calibrated rheological parameters are then used for predicting the evolution of a $10000 \mathrm{~m}^{3}$ potential event. Being the triggering area of the historical and potential events next to each other, similarity in lithological and morphological characteristics can be reasonably assumed.

The runout obtained by using the three rheological laws are then compared and discussed.

\section{From continuum dynamic modelling to the RASH3D code}

Continuum dynamic modelling has improved considerably in the past three decades and has gradually emerged as a useful tool for landslide runout analysis and risk assessment. With increasing attention and coinciding advances in computational capabilities, a large number of models (e.g. DAN, DAN-3D, DFEM, FLO-2D, RAMMS, SHWCIN, TITAN2D and many others) have been developed or are currently in development. Several of these models have included innovations that have significantly advanced both our ability to simulate real events and our fundamental understanding of rapid landslide processes (McDougall et al., 2008).

The continuum approach implies that the real moving mixture of the solid and fluid phases is replaced with a homogeneous continuum, whose rheological properties are intended to approximate the bulk behaviour of the real mixture, and motion is described using a model that consists of the balances of mass and momentum, namely

$\nabla \cdot \boldsymbol{v}=0$

$\rho\left(\frac{\partial \boldsymbol{v}}{\partial t}+\boldsymbol{v} \cdot \nabla \boldsymbol{v}\right)=-\nabla \cdot \boldsymbol{\sigma}+\rho \boldsymbol{g}$

where $\boldsymbol{v}\left(=v_{\mathrm{x}}, v_{\mathrm{y}}, v_{\mathrm{Z}}\right)$ denotes the velocity vector in an $x, y$ and $z$ reference system, $\sigma(x, y, z, t)$ is the Cauchy stress tensor, $\rho$ the mass density, and $\boldsymbol{g}$ the vector of gravitational acceleration.

Furthermore, assuming that the vertical structure of the analysed flow (i.e. depth) is much smaller than its characteristic length allows one to integrate the balance Eqs. (1)-(2) in depth and to obtain the so-called depth-averaged equations of motion (Savage and Hutter, 1989):

$$
\left\{\begin{array}{l}
\frac{\partial h}{\partial t}+\frac{\partial\left(\overline{v_{x}} h\right)}{\partial x}+\frac{\partial\left(\overline{y_{\mathrm{y}}} h\right)}{\partial y}=0 \\
\rho\left(\frac{\partial\left(\overline{v_{\mathrm{x}}} h\right)}{\partial t}+\frac{\partial\left(\overline{v_{\mathrm{x}}^{2}} h\right)}{\partial x}+\frac{\partial\left(\overline{v_{\mathrm{x}} v_{\mathrm{y}}} h\right)}{\partial y}\right)=-\frac{\partial\left(\overline{\sigma_{\mathrm{xx}}} h\right)}{\partial x}-\tau_{\mathrm{zx}}+\rho g_{\mathrm{x}} h \\
\rho\left(\frac{\partial\left(\overline{v_{\mathrm{y}}}\right)}{\partial t}+\frac{\partial\left(\overline{\left(\overline{y_{\mathrm{y}} v_{\mathrm{x}}} h\right)}\right.}{\partial x}+\frac{\partial\left(\overline{v_{\mathrm{y}}} h\right)}{\partial y}\right)=-\frac{\partial\left(\overline{\sigma_{\mathrm{y}}} h\right)}{\partial y}-\tau_{\mathrm{zy}}+\rho g_{\mathrm{y}} h
\end{array}\right.
$$

where $\overline{v_{\mathrm{x}}}, \overline{v_{\mathrm{y}}}$ denote the depth-averaged flow velocities in the $\mathrm{x}$ - and $\mathrm{y}$-directions ( $z$ is normal to the topography), $h$ is the 
fluid depth, $\tau_{\mathrm{zx}}, \tau_{\mathrm{zy}}$ the shear resistance stresses (transverse shear stress $\tau_{\mathrm{xy}}$ is neglected), $\overline{\sigma_{\mathrm{xx}}}, \overline{\sigma_{\mathrm{yy}}}$ the depth-averaged normal stress and $g_{\mathrm{x}}, g_{\mathrm{y}}$ the projection of the gravity vector.

In the present paper, the RASH3D (Pirulli, 2005; Pirulli et al., 2007), based on the above described assumptions, is applied for carrying out numerical analyses.

In RASH3D, the governing Eq. (3) are solved in an Eulerian framework on a triangular finite element mesh through a kinetic scheme based on a finite volume approach. A complete description of the numerical implementation used in the code and of the results of its testing against controlled experiments is given in Audusse et al. (2000), Bristeau and Coussin (2001), Mangeney et al. (2003), Pirulli (2005) and Pirulli et al. (2007).

\subsection{Rheological models}

Mud flows (e.g. Costa, 1984) and stony debris flows (e.g. Takahashi, 1991) are flows with a considerable proportion of fine material and flows where the coarser particles dominate the flow behaviour, respectively.

Mud flows may be described as a Newtonian or Bingham fluid in the laminar flow regime.

For large flow velocities a flow may show turbulent behaviour, suggesting that laminar flow resistance relations may be inappropriate (Rickenmann, 1999). For coarsegrained debris flows or granular debris flows where grain collisions dominate the flow behaviour a turbulent flow regime becomes the more appropriate. Nevertheless, the simple turbulent flow cannot alone describe the stopping of motion on gently sloping surfaces, so an additive Coulomb or friction term is however necessary for describing this mechanism.

It follows that to account for the fact that different debris flows may present different behaviours and that a debris flow behaviour may change from one regime to another within the same flow, additive combinations of basic flow regimes (i.e. frictional, turbulent, viscous) are discussed in the present paper.

In the simple Frictional rheology the resisting shear stress, $\tau$, at the base of the flowing mass is assumed to depend only on the normal stress (i.e. it is independent of velocity).

$\tau_{\mathrm{z} i}=-\left(\rho g_{\mathrm{z}} h \tan \varphi\right) \operatorname{sgn}\left(\overline{v_{i}}\right) \quad($ where $i=x, y)$

where $\rho$ is the material bulk density, $g_{z}$ is the normal projection to the slope of the acceleration due to gravity, $h$ is the flow depth, $\bar{v}\left(=\overline{v_{\mathrm{x}}}, \overline{v_{\mathrm{y}}}\right)$ is the depth-averaged flow velocity and $\varphi$ is the bulk basal friction angle.

Only one parameter, that is the bulk friction angle, has to be calibrated if this rheology is selected.
The Voellmy rheology adds to the above frictional term a turbulent term to account for all velocity-dependent factors of flow resistance. The resulting shear resistance stress is given by the following equation:

$\tau_{\mathrm{z} l}=-\left(\rho g_{\mathrm{z}} h \tan \varphi^{\prime}+\frac{\rho g{\overline{v_{i}}}^{2}}{\xi}\right) \operatorname{sgn}\left(\overline{v_{i}}\right) \quad($ where $i=x, y)$

where $\xi$ is the turbulence coefficient $\left(\xi=C^{2}\right.$, where $C$ is the Chézy coefficient), $\varphi$ ' which is equivalent to $\varphi$ in (4) above; the others terms are similar as in Eq. (4).

Two parameters, that are the friction angle and the turbulence coefficient, have to be calibrated if this rheology is selected.

Finally, in the Quadratic rheology the shear resistance stress is provided by the following expression:

$\tau_{\mathrm{zl}}=-\left(\tau_{\mathrm{y}}+\frac{K \eta\left|\overline{v_{i}}\right|}{8 h}+\frac{\rho g n^{2}{\overline{v_{i}}}^{2}}{h^{1 / 3}}\right) \operatorname{sgn}\left(\overline{v_{i}}\right)($ where $i=x, y)$

where $\tau_{\mathrm{y}}$ is the Bingham yield stress, $\eta$ is the Bingham viscosity, $n$ is the equivalent Manning coefficient for turbulent and dispersive shear stress components $\left(h^{1 / 3} / n^{2}=\xi\right)$ and $K$ is the flow resistance parameter; the others terms are similar as in Eq. (4).

The first and the second terms on the right hand side of Eq. (6) are the constant yield shear strength term and the viscous term as defined in the Bingham equation, respectively. The last term represents the turbulence contribution (O'Brien et al., 1993).

Three parameters, that are the yield stress, the viscosity and the Manning coefficient, have to be calibrated if this rheology is selected.

The above three rheologies are implemented in the continuum-mechanics-based code RASH3D that is applied in the present work.

RASH3D, as the other continuum mechanics runout codes, is unable of simulating landslide triggering mechanisms. That is, numerical simulations only concern the analysis of propagation and deposition of the flowing mass along the runout path. Nevertheless, effects of the above mechanisms on a debris flow propagation can be, in some measure, considered.

Taking into account that the more the runout length of a debris flow the less the influence of the triggering mechanism on the flow propagation (e.g. for long runout path the triggering mechanisms influences only the initial and relatively short stretch of the debris flow path), the triggering mechanism effect can be numerically reproduced changing the adopted rheology or the values of rheological parameters along the runout path. As an example, a movement whose triggering is characterised by sliding of a relatively massive volume that breaks during propagation and turns into a flowing mixture can be obtained using a Frictional rheology in the initial part of the path and then a Voellmy rheology. 


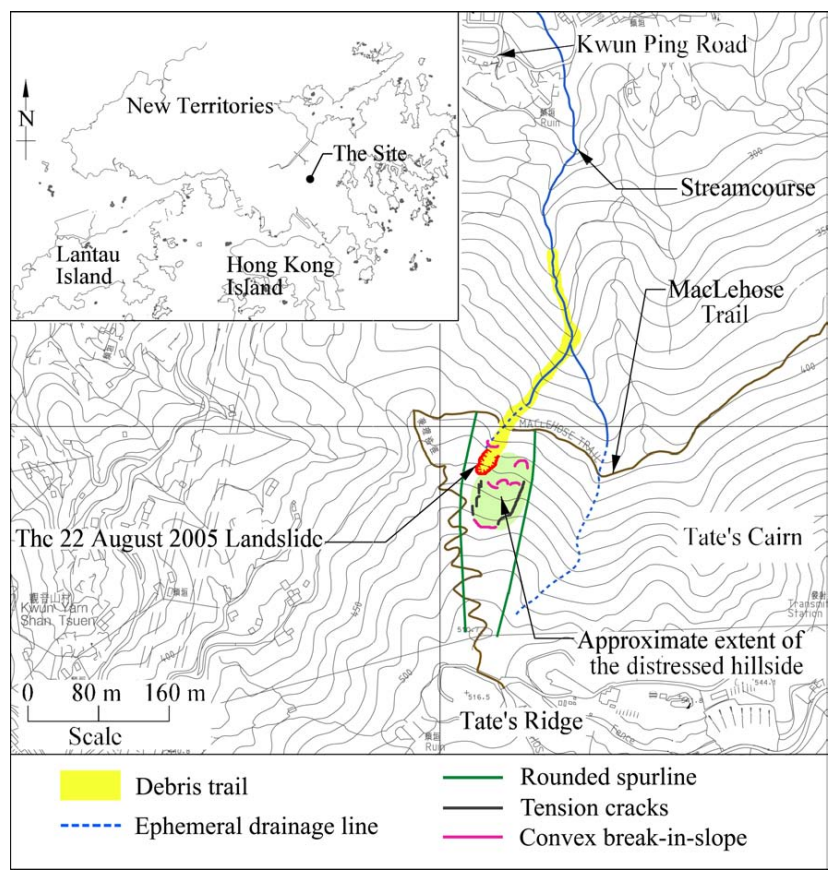

Fig. 1. Location and layout plans of the study area (modified after MGS, 2007).

This numerical application would increase the complexity of the problem, having to calibrate a large number of parameters of which little is known, and its validity could not be verified on site, since no case histories are sufficiently documented to allow for a detailed comparison among site and numerical results.

Furthermore, it is here evidenced that rheological properties used in continuum mechanics modelling are intended to simulate the bulk behaviour of an analysed landslide (from triggering to deposition) and do not correspond to the properties of any of the slide components. The use of average parameters, obviously without neglecting key factors for the phenomenon comprehension, has made continuummechanics based models particularly interesting for decision makers and hazard assessment in the last years.

\section{Description of the study area}

The August 2005 debris flow and the adjacent distressed area, which are object of the present study, are located on a north-northeast facing hillside, about $200 \mathrm{~m}$ to the north of Tate's Ridge and about $500 \mathrm{~m}$ south of Kwun Ping Road, Kwun Yam Shan, Hong Kong (Fig. 1).

The site is within, and adjacent to, a densely vegetated, linear topographical depression (about $60 \mathrm{~m}$ wide by $100 \mathrm{~m}$ in length) between two rounded spurlines and at the head of an ephemeral drainage line (Fig. 1).

The area is characterised by a deeply weathered thermally metamorphosed volcanic terrain with a mantle of colluvium. The colluvium is bouldery and about $5 \mathrm{~m}$ thick, while the

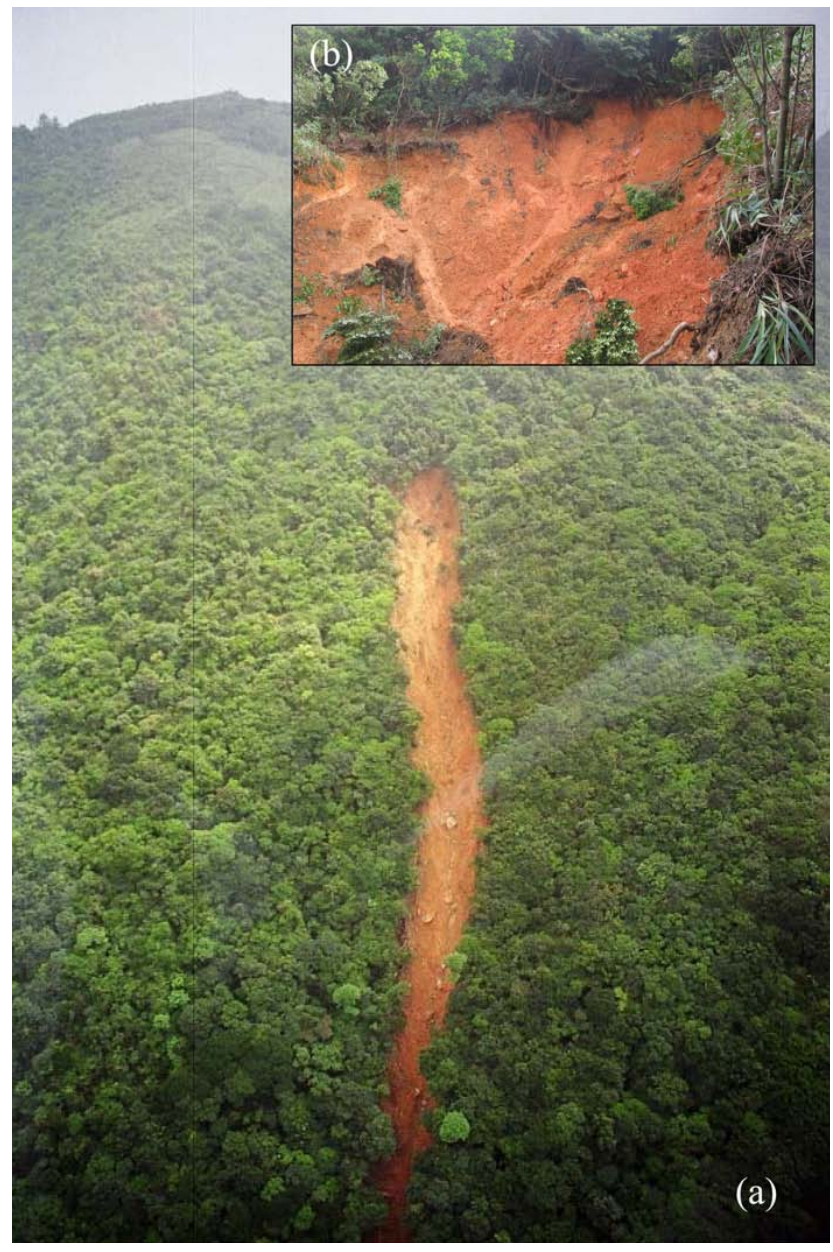

Fig. 2. The August 2005 debris flow: (a) oblique aerial view; (b) general view of the main scarp (modified after MGS, 2007).

underlying volcanic tuff saprolite is up to $30 \mathrm{~m}$ thick and in which corestone development appears relatively common. Many of the relict joints in the saprolite have a kaolin infill, a manganese oxide coating and are slickensided (MGS, 2007).

\subsection{The August 2005 debris flow at Tate's Cairn}

In the early morning of 22 August 2005, following heavy rainfall on 19 and 20 August 2005, a debris flow was reported in the west side of the mouth of the above mentioned topographical depression and above a convex break-in-slope (Figs. 1-2). The crown of the debris flow source area resulted at an elevation of about $448 \mathrm{~m}$ a.s.l. with the toe located at about $430 \mathrm{~m}$ a.s.l.

The aerial photographic records indicate that the debris flow occurred at about the same location as two smaller pre-1956 events. The previous instability and progressive degradation of the hillside appear typical of a hillside retreat process. Both surface runoff and subsurface flow would be directed towards the event site at the head of the drainage line 
and the presence of an interconnected subsurface drainage network would have promoted rapid groundwater flow to the debris flow site (MGS, 2007).

The August 2005 failure involved up to 5-m depth of colluvium with a total volume of about $2350 \mathrm{~m}^{3}$. A large portion of the displaced material (about $1350 \mathrm{~m}^{3}$ ) remained within the source area as intact rafts separated by a series of stepped tension cracks. The rest of the detached mass (about $1000 \mathrm{~m}^{3}$ ) entered the ephemeral drainage line below, and developed into a channelised debris flow (Fig. 1). The mass travelled a total distance of about $330 \mathrm{~m}$ down the drainage line and came to rest at two distinct boulder dams within the drainage line.

The difference in elevation between the landslide source and the end of the debris trail was approximately $138 \mathrm{~m}$, with a travel angle of about $24^{\circ}$ (Wong and Ho, 1996).

A detailed field mapping of volumes of material deposited along the runout path is presented in Fig. 3 .

As a consequence of the event an approximately $10-\mathrm{m} \mathrm{sec}-$ tion of the MacLehose Trail, that is about $30 \mathrm{~m}$ to the north of the toe of the August 2005 debris flow source area, was severed but no casualties were reported.

\subsection{The distressed hillside at Tate's Cairn}

A detailed inspection of the hillside above the August 2005 debris flow in March 2006 revealed an extensive system of tension cracks (Fig. 1). These tension cracks define an area of distressed hillside located on the southeast side of the August 2005 debris flow source area. The possible toe of this distressed hillside lies at an elevation between $430 \mathrm{~m}$ a.s.l. and $440 \mathrm{~m}$ a.s.l. and has an average inclination of about $20^{\circ}-25^{\circ}$ (Fig. 1).

The hillside above the distressed hillside is vegetated and is inclined at about $30^{\circ}$, gradually reducing to about $15^{\circ}$ near Tate's Ridge located about $100 \mathrm{~m}$ to the south. The hillside below the study area is densely vegetated and is inclined at about $30^{\circ}$ to $40^{\circ}$ that gradually reduces to $10^{\circ}$ to $20^{\circ}$ along the streamcourse.

The majority of the tension cracks as identified in March 2006 appeared fresh and may have occurred subsequent to the August 2005 debris flow. Evidence on the distressed hillside (viz. hummocky morphology, leaning trees, possible weathered patina on the southernmost tension crack), however suggests that initial movement of the distressed hillside most likely predates the August 2005 event and that initial development of at least part of the tension cracks may have been a result of earlier rainstorms. Given that the majority of the tension crack faces appeared fresh, the largest proportion of movement is postulated to have likely been triggered by the August 2005 rainstorm. The possibility of the fresh tension cracks being a reactivation of the distressed hillside due to the severe rainstorm in August 2005 cannot be ruled out (MGS, 2007).

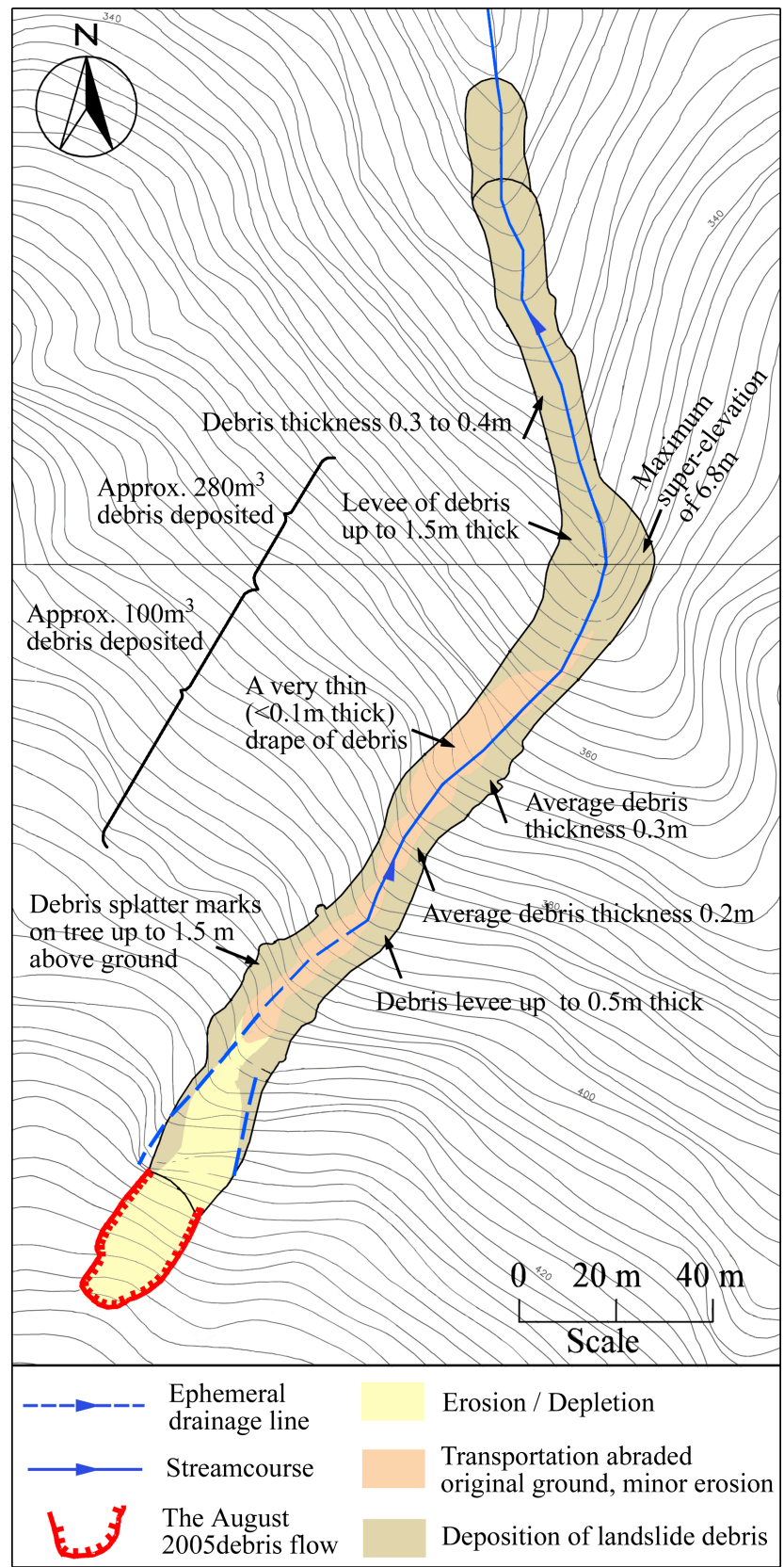

Fig. 3. The August 2005 debris flow - detailed field mapping of volume of material deposited along the runout path (modified after MGS, 2007).

Theoretical stability analyses of the distressed hillside were carried out to evaluate potential failures with respect to different possible groundwater regimes and shear strength parameters along a pre-defined failure surface. Based on the geological model, the failure along the interface of colluvium and tuff, at a depth of about $5 \mathrm{~m}$, would involve a volume of about $10000 \mathrm{~m}^{3}$ and would be plausible with a perched groundwater of about $1.3 \mathrm{~m}$ below ground surface (MGS, 2007). 


\section{Numerical analyses of historical and potential debris flows at Tate's Cairn (Hong Kong)}

A digital elevation model (DEM) with a 5-m-grid resolution, built on a Geographic Information System platform from the published 1:1000 topographic maps and spot heights, was available for the back-analysis of the August 2005 debris flow $\left(1000 \mathrm{~m}^{3}\right)$ and the forward-analysis of the distressed hillside potential debris flow $\left(10000 \mathrm{~m}^{3}\right)$.

As a general rule, calibration of rheological parameters have to ensure that the best simulation is obtained of the overall runout distance and distribution of velocities, flow depths and deposit thicknesses (e.g., Ayotte and Hungr, 2000). But, only on very rare occasions are these information simultaneously available. As an example, for the case history here analysed, available data concerned the overall runout distance and deposit thickness distribution (see Fig. 3).

It is well known that the higher the number of rheological parameters (e.g. Quadratic vs. Frictional), the greater the difficulty in constraining them by a systematic adjustment in the back analysis. Furthermore, the number of rheological parameter combinations that apparently gives a satisfactory numerical back-analysis grows up when the number of site information diminishes. That is, any of these combinations could be acceptable, if no information about the velocity, the depth distribution in the deposit and the physical state of the flowing mass is available.

For the August 2005 debris flow, the best combination of rheological parameters was selected ensuring the best simulation of not only the overall runout distance but also of the deposit thickness distribution. At first, results that were not able to reproduce the actual runout distance and spread of the mass in a satisfactory way were rejected. Then, the deposit thickness distributions obtained with the remaining combinations were compared with the actual distribution and other combinations were rejected. This allowed to select the best combination of parameters also when complex rheologies are used.

\subsection{Back-analysis of the August 2005 debris flow}

First the August 2005 debris flow is analysed to calibrate rheological parameters of each selected rheology (i.e. Frictional, Voellmy, Quadratic). The best results in terms of overall runout distance and deposit thickness distribution are obtained using:

- $\varphi=27^{\circ}$, in case of Frictional rheology;

- $\varphi^{\prime}=25^{\circ}$ and $\xi=1000 \mathrm{~m} / \mathrm{s}^{2}$, in case of Voellmy rheology;

- $\tau_{\mathrm{y}}=1.2 \mathrm{kPa}-\eta=40 \mathrm{Pas}-n=0.03$, in case of Quadratic rheology.

The calculated sequence of movements in terms of depth are visualized in Figs. 4, 5 and 6, respectively. In each figure, a

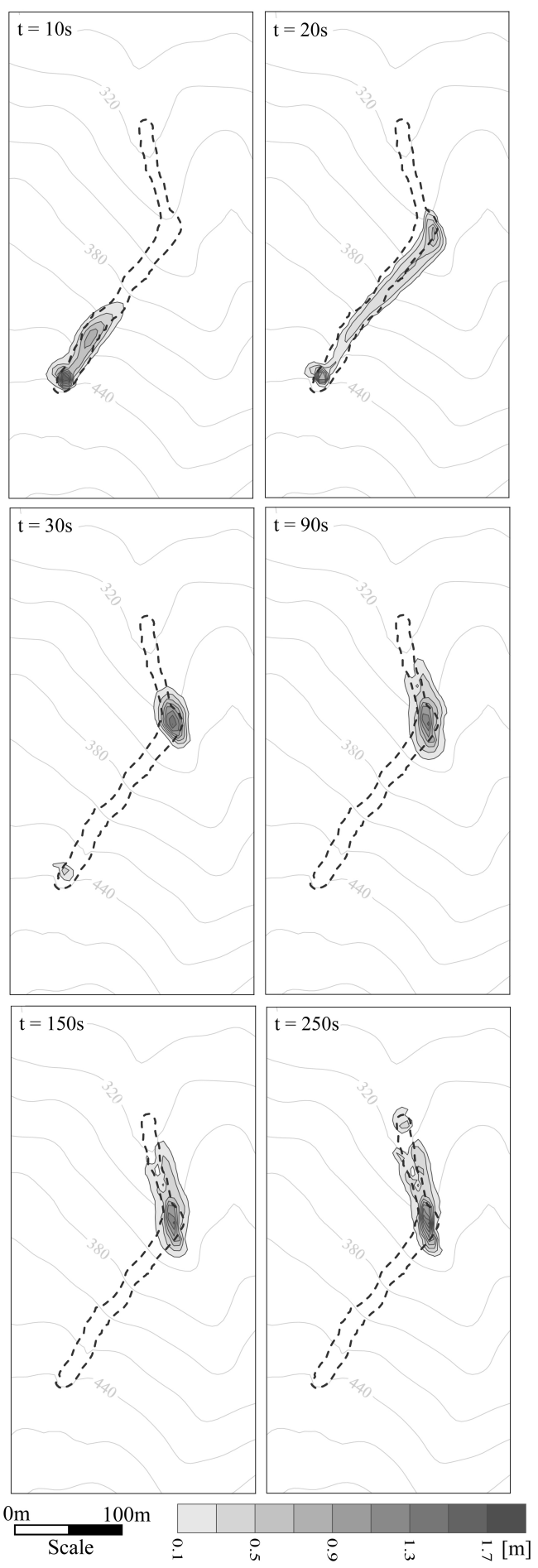

Fig. 4. The August 2005 debris flow - dilled depth contours of sliding debris (Frictional rheology). The dotted line indicates the extent of the real event (propagation + deposit).

splitting of the mass in the final part of the deposit emerges due to the existence of two boulder dams that were probably formed in previous landslide incident(s). 

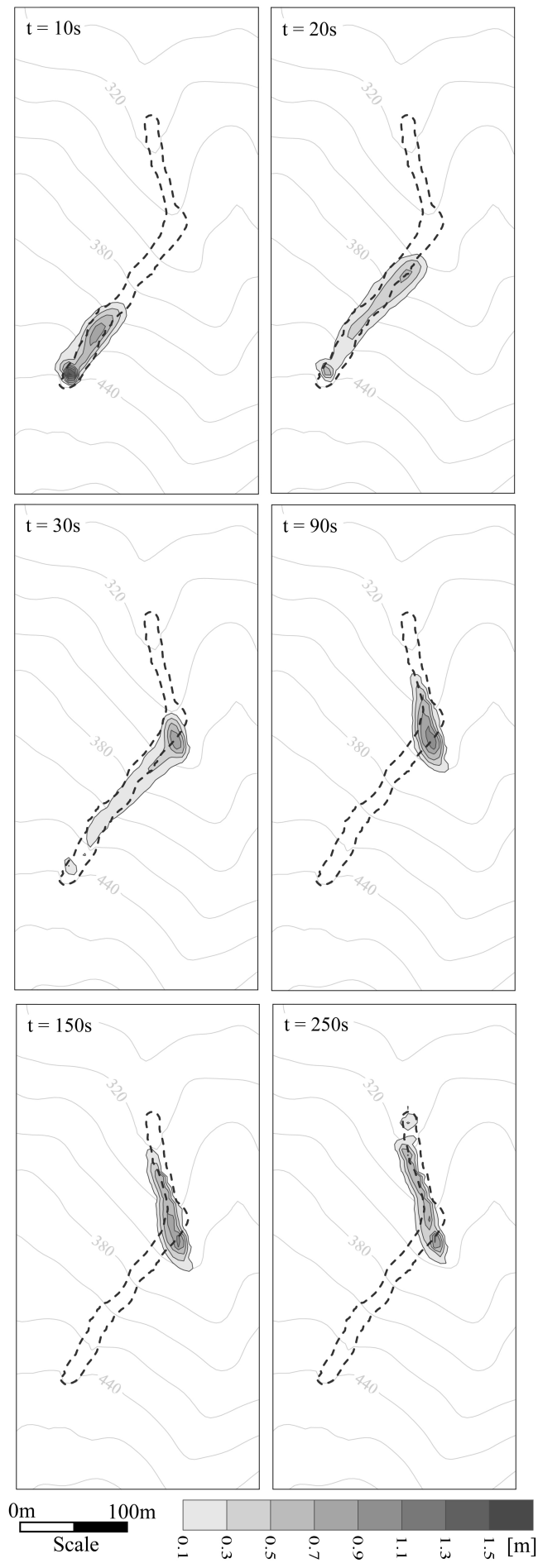

Fig. 5. The August 2005 debris flow - Filled depth contours of sliding debris (Voellmy rheology). The dotted line indicates the extent of the real event (propagation + deposit).

Observing the shape of the obtained deposits, it immediately emerges that the Quadratic is the more realistic solution. The Frictional and the Voellmy rheologies give too

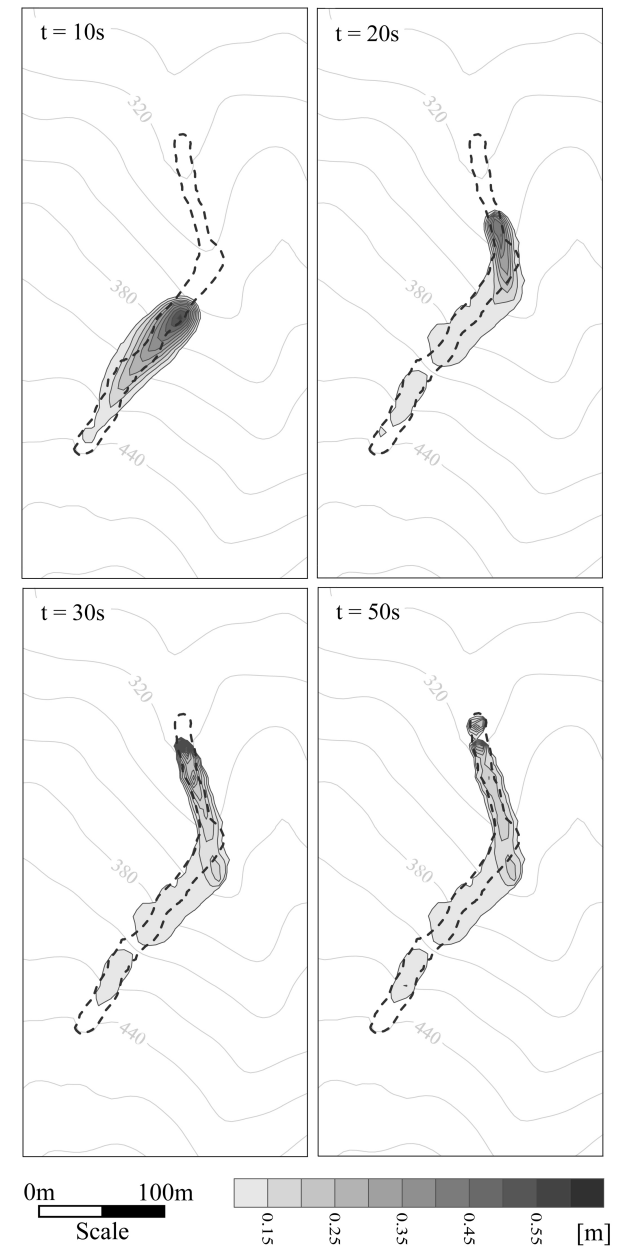

Fig. 6. The August 2005 debris flow - depth contours of sliding debris (Quadraticl rheology). The dotted line indicates the extent of the real event (propagation + deposit). Contours are at $0.05 \mathrm{~m}$ intervals.

short deposits: they are not able to simulate the accumulation of debris in the upper part of the runout path, which at the contrary emerges in the detailed field mapping of the event (Fig. 3). Besides, the Frictional solution gives an excessive deposit spread.

Concerning the deposit depth distribution, the Frictional rheology tends to produce deposits thick in the proximal part and thin in the front. The Voellmy rheology produces rather uniformly distributed deposits. The Quadratic model produces relatively uniform depth, leaving, thanks to the viscous term, an amount of deposits on the proximal part of the flow path. As to the deposit maximum depths, the three rheologies give results that differ in terms of both value and position; the higher value is reached in the proximal part of the Frictional deposit $(1.35 \mathrm{~m})$, the intermediate value is observed along the Voellmy deposit $(0.95 \mathrm{~m})$ and the lower value is in the distal part of the Quadratic deposit $(0.30 \mathrm{~m})$. 
None of the three rheologies is able to completely reproduce the deposit characteristics. The Voellmy and the Frictional do not produce good results in terms of neither deposit shape nor average depth of debris distribution, while the Quadratic produces the best results in terms of deposit shape and average depth of debris distribution but not in terms of maximum depth.

The calculated velocity trend evidences that velocities increase rapidly with a local maximum nodal velocity of $13.08 \mathrm{~m} / \mathrm{s}$ and a maximum mean velocity of $8.56 \mathrm{~m} / \mathrm{s}$ at $t=20 \mathrm{~s}$ using the Frictional rheology; a local maximum nodal velocity of $6.52 \mathrm{~m} / \mathrm{s}$ and a maximum mean velocity of $4.48 \mathrm{~m} / \mathrm{s}$ at $t=10 \mathrm{~s}$ using the Voellmy rheology; and a local maximum nodal velocity of $13.64 \mathrm{~m} / \mathrm{s}$ and a maximum mean velocity of $6.65 \mathrm{~m} / \mathrm{s}$ at $t=10 \mathrm{~s}$ using the Quadratic rheology. Unfortunately, information regarding movement velocity is not available and consequently no comments can be made on the above velocity field distributions.

\subsection{Analysis of the distressed hillside}

The above results show that past events can be modelled with reasonable accuracy by finding the matching parameters through trial and error. In fact, when comparing the model simulation results with observations of the natural debris flow, it is possible to achieve a reasonable agreement between main predicted and observed characteristics. However, it is still difficult to produce predictions of the most likely runout beforehand.

When back-analysed rheological parameters are used to run forward-analyses, a first uncertainty to be faced concerns the possibility that the potential event can have mixture composition and consequently flow characteristics (dynamic interaction between solid and fluid phases during propagation) different from those of the considered case history.

This is way the comparison among events located in the same basin, making improbable a large difference in mixture composition from one case to another, is here carried out and is suggested as rule.

Furthermore, to face the possible role of volume in changing the flow characteristics and consequently values to use for rheological parameters, the condition of no entrainment along the runout path has been assumed.

Entrainment, adding material with different characteristics (e.g. water content) to the flowing mass, is one of the main factors that can change both a flow volume and characteristics.

At first sight, flow characteristics and dynamics of large volumes can appear very different from those of small volumes. But, in the hypothesis that two masses, with a different volume and the same mixture composition, are released on a similar topography, the difference in volume does not play a major role on the rheological properties of the two flows, unless a change in flow composition originates along the runout path. In general, on an erodible bed, the entrainment capabi-

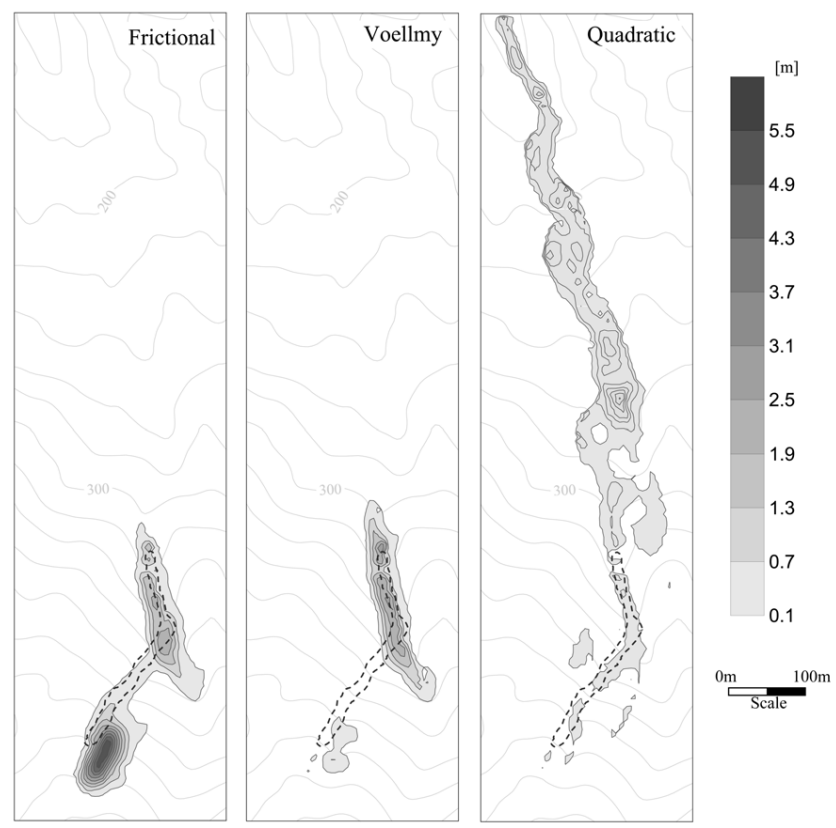

Fig. 7. Distressed hillside - filled depth contours of sliding debris. Comparison among Frictional, Voellmy and Quadratic rheologies using the best fit parameters obtained for the August 2005 debris flow. The dotted line indicates the extent of the August 2005 debris flow (propagation + deposit).

lities of the volumes are wider than those of small volumes, this is why the flow characteristics of the first appear very different from those of the second one.

On the base of the above observations, assuming that the historical and the potential investigated debris flows are characterised by no entrainment along the runout path and are similar in flow characteristics and dynamics (i.e. they have approximately the same mixture composition), the forwardanalysis of the distressed hillside is here carried out with the rheological parameters back-calculated for the August 2005 debris flows. The obtained deposits are visualized in Fig. 7.

Large differences in terms of overall runout distance emerge between the Frictional and the Voellmy solutions and the Quadratic one (Fig. 7). In particular, the first two define a rather similar runout, even if with the Frictional rheology much of the landslide volume remains in the source area. While, the frontal end of the debris flow runs beyond the available DEM domain when the third rheology is used.

Since the similarity in lithological and morphological characteristics of the two events is guaranteed (being the triggering area of the historical and potential events next to each other), the obtained results have induced an in-depth investigation on the role of landslide volume when using backanalysed rheological parameters for forward-analyses. In fact, assumed rheological values originate from a flowing volume that is 10 times smaller $\left(1000 \mathrm{~m}^{3}\right)$ than that of the distressed hillside $\left(10000 \mathrm{~m}^{3}\right)$. 


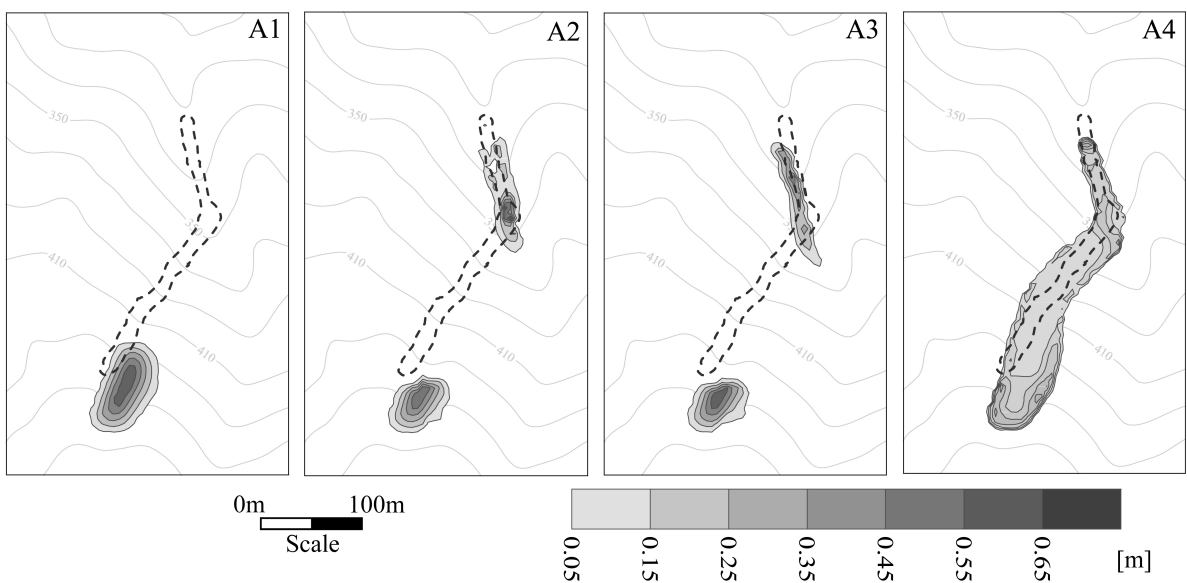

Fig. 8. Distressed hillside - Filled depth contours of sliding debris assuming a volume of $1000 \mathrm{~m}^{3}$ and the rheological parameters calibrated through the back-analysis of the August 2005 debris flow. The dotted line indicates the extent of the August 2005 debris flow (propagation + deposit). (A1) Triggering area, (A2) Frictional rheology, (A3) Voellmy rheology, (A4) Quadratic rheology.

The depth of the distressed hillside volume is then cut by $90 \%$ and a volume of about $1000 \mathrm{~m}^{3}$, with the same basal area, is tested. The propagation of the new volume $\left(1000 \mathrm{~m}^{3}\right)$ is then analyzed with the back-calculated parameters and results are represented in Fig. 8. It emerges that the three rheologies give again a similar runout distance when the historical and potential events have approximately the same volume.

\section{Discussion}

The single-phase approach to describe debris flows ignores experimental evidences of dynamic pressures arising from the grain collisions in granular flows (Iverson, 1997) which suggest that rheological relations that do not include such normal stress effects are an oversimplification (Naef et al., 2006). However, as pointed out by Hungr (2006) intergranular friction forces may implicitly be accounted for in the frictional and velocity-dependent flow resistance terms. As a consequence, if field data from the catchment can be used to calibrate the flow resistance coefficient, a one-phase model can be apply to estimate in a first step areas potentially affected by overhanging events. Nevertheless, being a flow behaviour widely influenced by both flow and slope characteristics, particular care is necessary for transferring backcalculated parameters to forward-analyses.

For the field case back-analysed in the present paper, where the event volume, the runout distance and some aspects of the deposition pattern (e.g. deposit thickness distribution) are known, three rheologies have been tested (i.e. Frictional, Voellmy, Quadratic). This has made possible some considerations on the role of each rheological parameter in simulating a flow characteristics and consequently some first indication on the dynamics of the studied debris flow. In fact, assuming that the dynamic effective friction angle of rapidly shearing dry rock fragments is about $30^{\circ}$ and considering that pore-fluid pressure can halve the shear strength, the bulk friction angles obtained in both the Friction $\left(27^{\circ}\right)$ and the Voellmy $\left(25^{\circ}\right)$ solutions would evidence a minor role of water pressure on the analysed event propagation. Furthermore, since transition from turbulent flow to laminar flow is numerically simulated with a gradual increment of the turbulence coefficient, $\xi$ (Voellmy rheology), or decrement of the Manning coefficient, $n$ (Quadratic rheology), the coefficient used in both the Voellmy $\left(1000 \mathrm{~m} / \mathrm{s}^{2}\right)$ and the Quadratic (0.03) solutions would evidence a flow in which the turbulent component has had a minor role in the energy dissipation respect to the frictional component. In fact, the calibrated rheological parameters have values that are more typical of laminar flow simulations (e.g. Pirulli and Sorbino, 2008).

The application of back-calculated rheological parameters to the potential event next to the triggering area of the historical event has instead highlighted that particular care is necessary in using back-calculated Quadratic parameters for prediction purposes.

Unlike fluids, granular materials can sustain a given stress without deforming. The transition between a static state $(v=0)$ and a flowing state is generally simply modelled, in depth-averaged models, as a function of the shear strength generated at the interface between the slope and the flowing mass and, in particular, it depends on the ratio of the resisting shear stress and the displacing shear stress. Motion is allowed only if the norm of the displacing shear stress exceeds the resisting shear stress (=flowing condition).

It is well known that the displacing shear stress directly depends on the flow depth; as a consequence, from the analysis of three rheologies adopted in the presented paper it results that:

- in case of a Frictional rheology (see Eq. 4), the resisting shear stress also directly depends on the flow depth $(h)$ 
and, consequently, $h$ does not influence and could be suppressed from the mass flowing condition;

- in case of a Voellmy rheology (see Eq. 5), the resisting shear stress is made of one term that directly depends on the flow depth (the frictional term) and one term that is independent of the flow thickness (the turbulent term). As a consequence, $h$ cannot be suppressed from the flowing condition and, since both the terms contribute in defining the resisting shear stress, the Voellmy resisting shear stress usually results higher than the Frictional resisting shear stress;

- in case of a Quadratic rheology (see Eq. 6), the Bingham yield stress is independent from the flow depth, while both the viscous and the turbulent terms of the resisting shear stresses depend on the inverse of the flow thickness. It follows that an increase of $h$ determines an increase of the displacing shear stress and a decrease of the resisting shear stress, and vice versa.

Since, flow characteristics being equal, the flow depth (especially the maximum depth that the flow can reach) can be considered representative of the moving mass volume, the above observations can be used to evidence that:

- the Frictional rheology is not influenced by flow depth/volume;

- the Voellmy rheology depends on flow depth/volume. An increase of $h$ determines both an increase of the displacing shear stress and of the resisting shear stress. In particular, in case of laminar flow the turbulent term vanishes (since a high value of the turbulent coefficient, $\xi$, is necessary for simulating this type of flow) and the Voellmy rheology gives a mass behaviour close to that obtained with a Frictional rheology. While, in case of a turbulent flow, the turbulent term contributes in defining the resisting shear stress;

- the Quadratic rheology is widely influenced by flow depth/volume. The larger is the moving mass volume, the larger is the flow depth (especially the maximum flow depth). Also the displacing shear stress must be larger the resisting shear stress is smaller.

Since, for a Quadratic rheology, displacing and resisting shear stresses have, respectively, a concordant and discordant trend, with respect to the flow depth/volume, particular care is necessary in transferring calibrated rheological parameters among cases dissimilar in volume.

The Frictional rheology does not present problems of this type. The same can be stated for a Voellmy rheology, in fact: it is based on a resisting shear stress whose formulation reflects that of the Frictional rheology and differences between the two rheologies derive from a term (the turbulent tern) that is independent of the flow depth.

\section{Conclusions and further developments}

The back-analysis of a $1000 \mathrm{~m}^{3}$ debris flow, located at Tate's Cairn, Hong Kong, and the forward-analysis of a $10000 \mathrm{~m}^{3}$ potential debris flow, located in the same basin, have been carried out to investigate the transferability of calibrated rheological parameters from a back-analysed case to a potential case.

To this aim, three different rheologies have been tested: Frictional, Voellmy and Quadratic. For the analysed case history, the back-calculated rheological parameters have resulted $\varphi=27^{\circ}$ for the Frictional rheology, $\varphi^{\prime}=25^{\circ}-\xi=1000 \mathrm{~m} / \mathrm{s}^{2}$ for the Voellmy rheology and $\tau_{\mathrm{y}}=1.2 \mathrm{kPa}-\eta=40 \mathrm{~Pa} \mathrm{~s}-n=0.03$ for the Quadratic rheology.

These results have made possible some first considerations on the dynamics of the analysed historical event. In particular, it has emerged that a frictional rather than turbulent behaviour has dominated the flow propagation. While, a viscous component has allowed deposition of debris along the runout path.

When used for prediction purposes, the above calibrated parameters do not have converged in a unique solution. In particular, the overrun of travel distance for the Quadratic rheology respect to the others has made evident that the Quadratic rheology, due to its mathematical formulation, is largely influenced by flowing volume size.

This point has underlined that in a calibration-based approach particular care is necessary in comparing events not only similar in lithological and morphological characteristics but also in those aspects that can assume a predominant role as a function of the selected rheology. On this regard, important indications have been obtained from the mathematical formulation of the applied rheologies.

To give a stronger support to the considerations made in the present paper, further developments of this research will entail the back-analysis of other well documented events. In particular, the analysis of case histories characterised by the presence of both small and large volumes will be carried out to give further support to the present conclusions and properly check how much the inverse dependence of the rheological law from the flow depth can really influence the mass propagation.

In any case, it is here further stressed that the calibrationbased approach can be considered a useful tool in landslide forward analysis and hazard assessment when particular care is used in its application.

Acknowledgements. The author is grateful to the Head of the Geotechnical Engineering Office and the Director of the Civil Engineering and Development Department, the Hong Kong SAR Government, for provision of the digital terrain models and permission to publish the information collected in this paper, to Oldrich Hungr for his precious suggestions on some key topics, Anne Mangeney (IPGP, France) and Marie-Odile Bristeau (INRIA, France) for having offered the use of the SHWCIN code, from which RASH3D has originated. 
Edited by: M. Pastor

Reviewed by: two anonymous referees

\section{References}

Audusse, E., Bristeau, M. O., and Perthame, B. T.: Kinetic schemes for Saint-Venant equations with source terms on unstructured grids, INRIA Report 3989, Natl. Inst. For Res. In Comput. Sci. and Control, LeChesnay, France, 2000.

Ayotte, D. and Hungr, O.: Calibration of a runout prediction model for debris-flows and avalanches, in: Proceedings of the Second International Conference on Debris-Flow Hazards Mitigation, Taipei, edited by: Wieczorek, G. F. and Naeser, N. D., A.A. Balkema, Rotterdam, 505-514, 2000

Benda, L. E. and Cundy, T. W.: Predicting depostion of debris flows in mountain channels, Can. Geotech. J., 27, 409-4171 1990.

Bristeau, M. O. and Coussin, B.: Boundary conditions for the shallow water equations solver by kinetic schemes, INRIA Rep. 4282, Natl. Inst. For Res. In Comput. Sci. and Control, Le Chesnay, France, 2001.

Cannon, S. H.: An empirical model for the volume-change behaviour of debris flows, in: Proceedings, Hydraulic Engineering, 93, San Francisco, 25-30 July 1993, edited by: Shen, H. W., Su, S. T., and Wen, F., American Society of Civil Engineers, New York, 2, 1768-1777, 1993.

Chen, H. and Lee, C. F.: Numerical simulation of debris flows, Can. Geotech. J., 37, 146-160, 2000.

Christen, M., Bartelt, P., and Gruber, U.: RAMMS - a Modelling System for Snow Avalanches, Debris Flows and Rockfalls based on IDL, Photogramm. Fernerkun., 4, 289-292, 2007.

Costa, J. E.: Physical geomorphology of debris flows, in: Developments and Applications of Geomorphology, edited by: Costa, J. E. and Fleisher, P. J., Springer-Verlag, New-York, 268-317, 1984.

Denlinger, R. P. and Iverson, R. M.: Granular avalanches across irregular three-dimensional terrain. 1 . Theory and computation, $\mathrm{J}$. Geophys. Res., 109, F01014, doi:10.1029/2003JF000085, 2004.

Fannin, R. J. and Rollerson, T. P.: Debris flows: some physical characteristics and behaviour, Can. Geotech. J., 30, 71-81, 1993.

Fannin, R. J. and Rollerson, T. P.: Assessing debris flow hazards in British Columbia: runout behaviour, in: Proceedings of the International Mountain Logging and Pacific Northwest Skyline Simposium, Campbell River, B.C., 13-16 May 1996, Forest Engineering Research Institute of Canada (FERIC), Special Report SR-116, 30-44, 1996.

Fannin, R. J. and Wise, M. P.: An empirical-statistical model for debris flow travel distance, Can. Geotech. J., 38, 982-994, 2001.

Hungr, O.: A model for the runout analysis of rapid flow slides, debris flows, and avalanches, Can. Geotech. J., 32, 610-623,1995.

Hungr, O.: Rock avalanche occurrence, process and modelling, Keynote Paper, in: Landslides from massive rock slope failure, NATO Science Series, edited by: Evans, S. G., ScarasciaMugnozza, G., Strom, A., and Hermanns, R., Springer, Netherlands, 2006.

Iverson, R. M.: The physics of debris flows, Rev. Geophys., 35(3), 245-296, 1997.

Iverson, R. M. and Denlinger, R. P.: Flow of variably fluidized granular masses across three-dimensional terrain: 1 . Coulomb mixture theory, J. Geophys. Res., 106, 537-552, 2001.
Körner, H. J.: The energy line method in the mechanics of avalanches, J. Glaciol., 26, 501-505, 1980.

Mangeney, A., Vilotte, J. P., Bristeau, M. O., Perthame, B., Bouchut, F., Simeoni, C., and Yerneni, S.: Numerical modelling of avalanche based on saint Venant equations using a kinetic scheme, J. Geophys. Res., 108(B11), 2527, doi:10.1029/2002JB002024, 2003.

McDougall, S. and Hungr, O.: A model for the analysis of rapid landslide runout motion across three-dimensional terrain, Can. Geotech. J., 41(6), 1084-1097, 2004.

McDougall, S., Pirulli, M., Hungr, O., and Scavia, C.: Advances in landslide continuum dynamic modeling (Special Lecture), in: Lansdlides and Engineered Slopes: From the Past to the Future, edited by: Chen, Z.-Y., Hodgson, K. W., Ho, K. K. Y., Li, Z.-K., and Wu, F.-Q., Taylor \& Francis Group, London, 2008.

MGS: Detailed Study of the 22nd August 2005 Landslide and Distress on the Natural Hillside above Kwun Ping Road, Kwun Yam Shan, Shatin, Maunsell Geotechnical Services Ltd., Landslide Study Report 5/2007, Geotechnical Engineering Office, Civil Engineering and Development Department, The Government of the Hong Kong Special Administrative Region, 138 pp., 2007.

Naef, D., Rickenmann, D., Rutschmann, P., and McArdell, B. W: Comparison of flow resistance relations for debris flows using a one-dimensional finite element simulation model, Nat. Hazards Earth Syst. Sci., 6, 155-165, doi:10.5194/nhess-6-155-2006, 2006.

O'Brien, J. S., Julien, P. Y., and Fullerton, W. T.: Two-dimensional water flood and mudflow simulation, J. Hydrol. Eng., 119(2), 244-261, 1993.

Perla, R., Cheng, T. T., and McClung, D. M.: A two-parameter model of snow avalanche motion, J. Glaciol., 26, 197-207, 1990.

Pirulli, M.: Numerical modelling of landslide runout, a continuum mechanics approach, Ph.D. thesis, Department of Structural and Geotechnical Engineering, Politecnico di Torino, Italy, 2005.

Pirulli, M., Bristeau, M. O., Mangeney, A., and Scavia, C.: The effect of earth pressure coefficient on the runout of granular material, Environ. Modell. Softw., 22(10), 1437-1454, 2007.

Pirulli, M. and Sorbino, G.: Assessing potential debris flow runout: a comparison of two simulation models, Nat. Hazards Earth Syst. Sci., 8, 961-971, doi:10.5194/nhess-8-961-2008, 2008.

Pirulli, M.: Morphology and substrate control on the dynamics of flow-like landslides, J. Geotech. Geoenviron., 136(2), 376-388, 2010.

Rickenmann, D.: Empirical relationships for debris flows, Nat. Hazards, 19(1), 47-77, 1999.

Rickenmann, D.: Runout prediction methods. in: Debris-Flow Hazards and Related Phenomena, edited by: Jakob, M. and Hungr, O., Praxis, Chichester, 305-324, 2005.

Savage, S. B. and Hutter, K.: The motion of a finite mass of granula material down a rough incline, J. Fluid Mech., 199, 177-215, 1989.

Takahashi, T.: Debris Flow, Balkema, Rotterdam, 1991.

Van Gassen, W. and Cruden, D. M.: Momentum transfer and friction in the debris of rock avalanches, Can. Geotech. J., 26, 623$628,1989$.

Wong, H. N. and Ho, K. K. S.: Travel distance of landslide debris, Landslides, edited by: Senneset, K., Balkema, Rotterdam, 1, 417-422, 1996 